\title{
WAWASAN HIDUP JAWA \\ DALAM TEMBANG MACAPAT \\ Oleh:Suwardi
}

\section{Abstrak}

Nama-nama tembang macapat (TM) memang tampak menggoda. Boleh jadi nama itu diciptakan oleh para wali. Maka bukan mustahil jika dibalik nama itu termuat wawasan hidup. Setidaknya wawasan hidup orang Jawa (wali sanga) pada saat itu. Pada dasarnya nama.

TM memuat dua macam wawasan hidup. Pertama, sebagai wawasan hidup berdakwah. Kedua sebagai wawasan perjalanan hidup. Keduanya jauh berbeda dalam upaya penafsiran, teutama dari segi urutan TM sebagai wawasan hidup berdakwah berisi anjuran tentang "metode" berdakwah, yakni: dakwah hendaknya mengingat empan papan, hati-hati mengeluarkan (Mijil) kata, jangan menyimpang (pangkur) dari Al-Qur'an dan Hadits), menjaga (kinanthi) agar tidak bermusuhan, disampaikan secara enak (dhandhanggula), memberi harapan agar awet muda(sinom), mendorong agar suka mengeluarkan infak (Armaradana), mendorong agar menjauhkan hawa nafsu (Megatruh), mendorong agar menghindarkan M-5 (Durma, memberi pengertian agar tidak merasa berat (Maskumambang) beribadah, menunjukkan jalan mencapai kesempurnaan (Pucung).

TM sebagai wawasan perjalanan hidup mengisyaratkan bahwa hidup itu bergerak/berproses dari sebelum "ada" sampai "tidak ada". Perjalanan hidup manusia itu: Mijil hidup bermula dari pria/wanita tertarik kepada lawan jenis), mengeluarkan 'isi hati', menyerahkan segalanya, dan menanamkan benih kasih sehingga terjadi kelahiran. Sinom, usia muda, sering mudah goyah, membutuhkan tauladan, sering berhias, Asmaradana, usia remaja biasanya butuh hiburan, dan ingin hidup yang enak. Kinanthi, usia menginjak dewasa, ia ia mulai ragu-ragu memilih jodoh, jika telah menemukan kekasih yang seimbang, keduanya akan memasuki pelaminan, menanamkan "rasa sejati". Dhandanggula, masa jaya-jayanya seseorang. Ia benar-benar merasakan manisnya (nikmat) hidup. Pada saat telah hidup berumah tangga, pasangan itu akan bebas memadu kasih, dalam berumah tangga bujukan diperlukan), terlebih lagi saat berhubungan seks yang sering hanyut dalam impian indah, maksudnya agar mendapatkan buah 'asih'/anak) yang mursid, namun bukan mustahil jika saat itu pula ada gangguan keluarga yang menyedihkan. Situasi ini justru ujian bagi pasangan untuk segera memikirkan bekal yang akan dibawa nanti. Gambuh, artinya tahu. Masa ini orang Jawa menyebut "gambuh salwiring kawruh", artinya sudah banyak makan garam. Oleh sebab itu ia sering "mendhita", banyak memberi petuah ketika "momong" anak cucu. Durma, usia tua biasanya telah mundur (menghindar) dari segala keinginan (nafsu) yang kurang baik. Saat ini perhatian dicurahkan untuk "nggayuh" kesempurnaan hidup. Maskumambang, manusia sudah "ngambang" (menjelang kematian), mungkin hidupnya tinggal menunggu waktu dan kurang berarti. Kepasrahan 
pun terjadilah. Megatruh, artinya perpisahan jiwa dan raga (mati). Pada saat ini manusia akan ada tanda-tanda khusus bila telah akan dipanggil. Pocung,

||||||||||||||||||
artinya jika orang telah mati akan dipocong atau dibungkus seperti
masih ada alam lagi yang akan dilewati yaitu alam pangrantunan dan alam
rambangan (yaumul khisab), akhirnya selesai tugas manusia di alam akherat.

\section{A. Pendahuluan}

Sekalipun ada yang bergumam; apalah arti sebuah nama, namun jika berhadapan dengan nama tembang macapat (selanjutnya disingkat TM) kita akan tergoda. Coba saja, jika berhadapan dengan TM: Mijil, mungkinkah ini ditafsirkan ke arah kelahiran manusia, karena mijil berarti 'lahir'. Semula, boleh jadi nama TM itu diciptakan oleh para wali dan atau oleh orang Jawa yang hebat. Orang Jawa yang berkharisma serta memiliki pemikiran mendalam terhadap kehidupan. Maka bukan mustahil jika dibalik nama TM termuat wawasan hidup. Setidaknya wawasan hidup orang Jawa yang didasarkan pengalaman hidup mereka yang panjang. Perlu diketahui, jika wawasan berarti cara pandang dan atau pandangan (KBBI, 1989:1010), maka wawasan hidup Jawa sesungguhnya juga identik dengan pandangan hidup Jawa. Pandangan hidup Jawa mengenal tiga segi, yaitu metafisika, epistemologi, dan aksiologi (Ciptoprawiro, 1986: 22-26). Metafisika adalah wawasan ontologi yang mencoba berpikir mencari 'ada' tentang Tuhan, manusia, alam semesta. Epistemologi, yaitu wawasan tentang bagaimana proses kehidupan. Aksiologi adalah wawasan nilai kehidupan.

Seiring dengan pendapat tersebut Sujamto (1992:55) menjelaskan bahwa wawasan metafisika Jawa, di antaranya dapat ditinjau secara filogenistis (proses evolusi). Wawasan ini terkait dengan hakikat hidup manusia. Hidup itu 'bergerak' dan berevolusi dari 'awal' sampai 'akhir'. Proses ini oleh Sastroamidjojo (1973:69) disebut 'perjalanan hidup'. Persoalannya sekarang, apakah nama TM akan melukiskan wawasan hidup demikian. Terlebih lagi, sekarang telah banyak variasi nama TM, mungkinkah hal ini juga memuat wawasan hidup yang bermakna.

\section{B. Aspek Historis, Makna, dan Jenis Tembang Macapat}

Secara historis, Sastrosupadmo (1974: 15) menginformasikan bahwa TM telah ada sejak zaman Majapahit. Pernyataan ini sebenarnya masih perlu dipertajam lagi, karena pada zaman Majapahit ada sebagian cendekiawan yang berpendapat bahwa saat itu yang lebih berkembang adalah kidung. Akan 
tetapi memang bukan mustahil jika, TM itu ada sejak 1500 SM, ketika masyarakat Jawa masih berpaham animisme dan dinamisme. Bahkan boleh jadi TM merupakan kelanjutan dari bentuk kidung, sehingga pada gilirannya muncul sastra suluk yang bermetrum macapat (Jumiran, 1996: 15).

Sedangkan Poerbatjaraka (Widayati, 1993:1) berpendapat munculnya kidung bersamaan TM. Lebih lanjut Poerbatjaraka (Suharjendra, 1996:1) menyatakan bahwa TM muncul sejak zaman kerajaan Demak, kemudian berkembang ke Pajang, Mataram, Surakarta, dan Yogyakarta. Pujangga terakhir yang menggunakan TM adalah R.Ng Ranggawarsita.

Salam (1960:2) menyatakan bahwa TM Asmaradana dan Pucung adalah ciptaan Sunan Giri. Sedangkan TM Sinom dan Kinanthi ialah ciptaan Sunan Muria. Hal ini sejalan dengan asumsi Hasyim (1974: 34-35), namun ia menambahkan bahwa TM Mijil diciptakan oleh Sunan Kudus, Dhandhanggula oleh Sunan Kalijaga, Durma oleh Sunan Bonang, Maskumambang oleh Sunan Kudus, Pangkur oleh Drajat, sedangkan Gambuh dan Megatruh tidak dijelaskan.

Sedangkan Poedjasoebroto (1978:194-207) menjelaskan Pocung dan Mijil ciptaan Sunan Gunung Jati, Megatruh, Gambuh, dan Kinanthi ciptaan Sunan Giri. Maskumambang ciptaan Sunan Majagung. Persamaannya terletak pada Asmaradana, Durma, dan Dhandhanggula.

Kendatipun ada sedikit perbedaan, kedua pendapat tersebut akan mengarahkan perhatian cendekiawan Jawa untuk berkesimpulan sementara bahwa TM memang ciptaan para Wali yang besar perhatiannya terhadap seni Jawa. Sejak itu para Wali Sanga, mulai berkiprah menyebarkan agama Islam.

Hal demikian memang sulit dipungkiri, sebab makna kata "macapat" semula adalah berkumpul dengan menyuarakan puji-pujian. Makna ini berasal dari jarwa dhosok, macapat, yaitu dari kata ma (menuju) dan capet (maya atau ghaib). Artinya, puji-pujian kepada yang ghaib, yaitu Tuhan. Makna demikian juga relevan dengan situasi masyarakat Jawa ketika belum masuk agama Islam. Sedangkan pada saat agama Islam telah berkembang, bukan hal yang aneh jika puji-pujian itu diwujudkan pada TM yang berisi rohani, yaitu sastra suluk (Jumiran, 1996: 3). Kendatipun demikian, memang sulit ditentukan, mungkinkah sastra suluk sebagai tonggak kelahiran TM.

Makna macapat memang mengalami pergeseran. Hardjowijono (1994: 3) menafsirkan macapat berkaitan dengan cara membaca (melagukan) 
empat-empat, yaitu perhentian nafas pada empat suku kata-empat suku kata. Dalam hal ini macapat yang membaca empat-empat itu harus diwaca

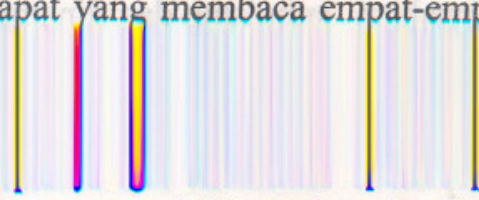

ada perubahan kata pat menjadi pet (cepet). Cepat yang dimaksud, seperti diterangkan Suharjendra (1960: 19) yaitu tidak banyak luk.

Penafsiran demikian juga barasalan karena dalam TM diikat oleh berbagai aturan ketat, seperti guru lagu, guru gatra dan guru wilangan (Prabowo, 1992:66-67). Dengan aturan yang ketat ini justru membuat TM semakin digemari orang Jawa, yakni tingkeban, kelahiran, dan Ultah.

Pada perkembangan selanjutnya TM tidak saja digunakan untuk mengungkapkan sastra Jawa tradisional (Laginem, 1992: 159), melainkan menurut Darmoatmodjo (1974, Jaya Baya 12 Nopember) juga dipakai lomba, dengan mengutamakan vokal (cara membaca). Kenyataan ini yang mendukung TM memiliki kedudukan tersendiri dalam masyarakat Jawa (Darusuprapto, 1983: 15). Eksistensi demikian dimungkinkan yang membuat TM sampai sekarang masih hidup (Prabowo, 1993: 29).

Menurut Serat Rama hanya dijelaskan sebagian saja dari nama TM, yakni: "doek semana doeroeng ana Midjil, Pangkoer miwah Sinom, Dhandhanggoela Doerma lan Kalanthe, Gambuh Megatroeh Maesa-langit, doeroeng ana lahir, kabeh tembang kidung" (Jasadipura, XXV: Mijil 114).

Jenis TM yang berurat berakar dalam masyarakat Jawa bervariasi. masih Arintoko (1982:1) dan (1983:1) menyatakan hanya ada 9 jenis yang baku, sedangkan 6 lainnya tidak baku. Pendapat ini disetujui pula oleh Josodipura (DL, 1990: Nop) dan Sujarwi (197: 3). Mungkinkah bilangan 9 itu juga terkait dengan penciptanya, yaitu Wali sanga ? Bagaimana pula dengan pendapat Prawiradisastra (1993:1-23) yang memaparkan 15 jenis TM. Mungkinkah semua jenis itu memuat wawasan hidup Jawa.

\section{TM sebagai Wawasan Berdakwah}

Nama-nama TM, menurut Poedjasoebroto (1978:194-207) berkaitan dengan wawasan hidup yakni tentang dakwah. Hal ini dapat ditelusur dari arti kata tembang yaitu seperti halnya karangan bunga. Di antara karakteristik bunga adalah berbau harum. Oleh sebab itu para wali menyarankan agar dakwah Islam dilakukakan seperti menaburkan bunga yang harum, yang menyenangkan, menggembirakan dan enak didengar. Sebaiknya dihindarkan dakwah secara polos, kasar, dan disertai memaki-maki, dan menyindir-nyindir sampai melukai hati.

Macapat berasal dari kata "mancapat" = man + ca + pat, ini 
jarwodhosok (otak-atik) dari kata iman + panca + pathokan. Dari "otakatik" ini tersirat bahwa dalam dakwah permulaan yang harus diperhatikan adalah Rukun Iman, Rukun Islam, yang lima (panca) sebagai pedoman (patokan). Secara rinci, nama-nama TM memberikan wawasan hidup berdakwah sebagai berikut:

Mijil berarti "keluar". Kata "keluar" terkandung faktor-faktor waktu, tempat dan keadaan, maka dalam memberikan dakwah Islam harus mengingat faktor : (a) waktu yang sesuai, misalnya jangan sampai menerjang pendek atau jangan menggunakan waktu yang sangat diperlukan sendiri oleh yang bersangkutan atau pada waktu ada kejadian yang tidak sesuai atau yang dirasa kurang pada tempatnya, (b) tempat yang berarti "empan-papan" dimana dakwah itu sedang dilaksanakan perlu memilih tempat yang cukup untuk menampung pendengar dan bebas gangguan, (c) keadaan orang yang menerima dakwah, umurnya, tingkat pengetahuannya, golongannya dan sebagainya. Dalam hal ini bahannya harus sesuai jangan "meloncat jauh" dari pengetahuan mereka. Konon, Mijil diciptakan oleh Sunan Gunung Jati di Cirebon. Mijil artinya keluar, yang mengandung makna, jika bicara jangan asal "mijil" saja atau asal bicara saja. Orang yang bertugas dakwah harus sanggup, sedia berani keluar dan mengeluarkan apa yang diperlukan.

Pangkur yang berasal dari nyimpang + mungkur, artinya dakwah jangan sekali-kali menyimpang dan meninggalkan isi Qur'an dan Hadits, namun simpangilah serta tinggalkanlah kejahatan. Pangkur diciptakan Sunan Muria yang teguh sekali dalam memegang dan melaksanakan ajaran Islam menurut Qur'an dan Hadits.

Kinanthi yang berasal dari kata kanthi diberi sisipan in, menjadi "kinanthi", artinya dikanthi, digandheng atau disertai/ditemani. Maksudnya, bagi orang-orang yang masih "buta" dari petunjuk Allah harus ditemani untuk dituntun menuju kepada hidup beragama. Dalam dakwah hendaknya berusaha mengadakan teman baru, tidak bermusuhan; dan sebaiknya agar didekati dengan dasar hati. Kinanthi diciptakan oleh Sunan Giri. Ia wali yang sangat terkenal di kalangan Rakyat karena sifat-sifatnya yang sesuai untuk mendekati rakyat yaitu bijaksana, ramah dan berbudi halus.

Dhandhanggula yang berasal dari dhandhang dan gula berarti pengharapan akan yang manis. Dakwah yang diberikan secara enak dan menyenangkan akan membawakan harapan untuk menuju kebahagiaan. Dhandhanggula ciptaan Sunan Kalijaga.

Sinom, berarti daun muda (pupus) pohon asam atau rambut halus di 
atas dahi wanita, yang mengandıng arti bahwa dakwah yang mengembirakan akan meresapkan rasa Agama, yang

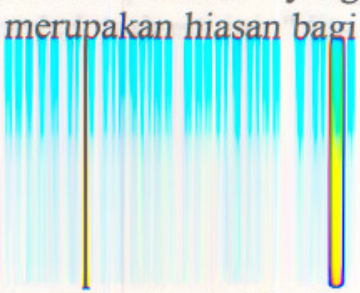

hidup manusia dan menjadikan manusia yang penuh harapan (optimis) dan tampak awet muda, karena bersih lahir batin. Sinom ciptaan Sunan Giri.

Asmaradana berasal dari kata asmara + dana berarti cinta + memberi $=$ senang memberi. Dakwah yang berhasil akan dapat menjadikan manusia yang suka memberi atau suka mengeluarkan infak, derma zakatfitrah, penerangan, suka menolong sesama manusia, karena Allah, ikhlas, tanpa rasa takabur. Asmaradana disusun oleh Sunan Giri.

Megatruh berasal dari kata megat - ruh, berarti memisahkan Rokh atau pemikiran yang tidak baik atau menaham hawa nafsu. Ajaran Islam pada pokoknya membawakan keimanan untuk menjalankan ibadah dengan menjauhkan hawa nafsu, berbuat baik dengan mentaati perintah Allah dan menjauhi kejahatan serta menghindari larangan Allah dan menjauhi Ajaran Iblis. Megatruh ciptaan Sunan Giri.

Durma berasal dari kata: dur + ma, artinya mundur dari M-5 yaitu: (a) Madon (berzina), (b) Minum (minuman keras) , (c) Madat (menghisap obat yang memabukkan), (d) Main (berjudi), (e) Maling (Mencuri). Durma ciptaan Sunan Bonang, dari sini bisa ditafsirkan bahwa menjauhi M-5 itu menuju kemenangan (baboning kemenangan = Bonang)

Maskumambang berarti emas yang terapung, maknanya karena ajaran Islam itu indah dan baik-baik betul, sekalipun berat, asal ada jiwa mengabdi kepada Allah (ibadat), maka semua itu menjadi ringan. Maskumambang ciptaan Sunan Maja Agung.

Pocung berarti : mati (dipocong = dibungkus mori putih, luar dan dalam suci), atau puncak (sudah yang tertinggi, sudah habis) atau sempurna. Maknanya ajaran Islam menuju pada kesempurnaan hidup di dunia dan akhirat, kesempurnaan dalam arti kebahagiaan. Pocung karangan Sunan Gunung Jati.

Bertolak dari pembahasan tersebut, dapat diketengahkan bahwa TM menggambarkan wawasan hidup epistemologi, yaitu bagaimana manusia mencari pengetahuan tenang Tuhan. Pengetahuan ini diwujudkan melalui metode dakwah yang mendasarkan pada TM. Proses ini yang dikenal dengan pendekatan diri kepada Tuhan agar manusia menjadi sempurna.

Hal demikian memang dapat dipahami, karena pada awalnya wali sanga dalam menanamkan ajaran justru dapat manjing ajur-ajer dengan masyarakatnya. Mereka berusaha mendalami TM (seni). Kenyataan ini 
merupakan gambaran pula bahwa TM berkaitan pula dengan falsafah nilai khususnya wawasan estetika.

\section{TM Sebagai Wawasan Perjalanan Hidup}

Nama-nama TM menurut Supadjar (1996:5) secara keseluruhan juga menggambarkan tahap-tahap perjalanan hidup manusia. Mijil (keluar/lahir), Sinom (masa muda), Maskumambang (penuh purba diri), Asmaradana (dana asmara), Dhandhanggula (mendendangkan kemanisan iman/hidup "Hamemamyu hayuningrat), Durma (mundur, mulai mengundurkan diri), Pangkur (mungkur/ meninggalkan hal-hal keduniawian), Gambuh (faham, tahu benar), Pocung (dipocong), dan yang terpenting Megatruh (memisah ruh/OB "Out of Body"), dan Kinanthi (amalan apa yang akan dibawa).

Penafsiran yang mendasarkan othak-athik mathuk tersebut agak berbeda dengan pendapat Guritno (1995:34), yakni: Mijil(awal kelahiran manusia), Maskumambang (anak kecil biasanya tak berdaya seperti "kemambang" sehingga butuh pertolongan, Kinanthi (anak tadi hanya menurut kehendak ayah-ibu), Sinom (usia muda mulai berkembang iman dan ilmunya), Asmaradana (mulai tertarik kepada lawan jenis), Durma (kemauan keras untuk bersenggama), Dhandhanggula (mulai menanamkan benih kasih), Gambuh (bersetubuh seperti halnya curiga manjing rangka rangka manjing curiga, nikmat betul), Pangkur (mulai menyingkirkan hawa napsu), Megatruh (perpisahan jiwa dan raga, mati), dan Pocung (telah dibungkus main kafan putih).

Wawasan hidup TM tersebut belum menggambarkan variasi TM yang ada sekarang. Padahal telah ada berbagai variasi jenis TM Itulah sebabnya, bagian ini akan membicarakan wawasan hidup dalam TM menurut macam-macamnya, yaitu:

Mijil, terdiri atas : (a) Mijil Kingkin, yaitu awal mula laki-laki mulai tergoda, memperhatikan, tertarik, jatuh cinta (kasmaran) pada wanita (atau sebaliknya) kekasihnya, (b) Mijil Wedharingtyas mengeluarkan/menumpahkan 'isi hati' untuk hidup bersama, (c) Mijil Raramanglong, wanita yang telah hidup bersama akan menyerahkan segalanya untuk suami, (d) Mijil Sekarsih, jika telah 'seia-sekata', pasangan suami isteri akan menanamkan benih kasih (memadu kasih) yang pada akhirnya akan melahirkan anak. Inilah awal kelahiran yang dinamakan hidup.

Sinom, yaitu usia anak tadi masih kecil (muda). Muda berarti masih bodoh, sehingga ada : (a) Sinom Ginonjing, usia anak yang mudah 
goyah, rasa, karsa dan pikiran belum stabil, (b) Sinom Kentar, oleh karena mudah goyah, anak dapat kentar $(k e l i)$ atau mudah terbawa arus. Dan mudah

terpengaruh karena masih senang rubuh-rubuh gedhang, (c) Sinom Grandhel, kata grandhel berarti bergantung, anak yang mudah terombangambing tersebut membutuhkan 'gantungan', mereka masih bergantung pada orang tua dan membutuhkan tauladan, (d) Sinom Pangrawit, rawit artinya halus dan indah, maka saat ini anak mulai berkembang rasanya. Ia mulai berhias/bersolek diri.

Asmaradana, yaitu usia anak remaja. Remaja ini telah memperhatikan lawan jenis, maka ada : (a) Asmaradana Bawaraga (sedih), ia mulai berkembang hatinya sering susah, karena itu ada (b) Asmaradana Panglipur, yaitu senang mencari hiburan untuk melampiaskan asmaranya, pada saat ini pula sampai : (c) Asmaradana Kedhaton, yakni merasakan/berangan-angan ingin hidup yang indah, enak. Itulah sebabnya, masa ini merupakan (d) Asmaradana Slobog (lubang), pintu awal memasuki/peralihan ke masa dewasa. Masa untuk masuk ke jenjang perkawinan.

Kinanthi, adalah usia seseorang menginjak masa masa dewasa (baliq). Ia telah berkewajiban mencari bekal (amal) yang akan "dikanthi" menuju akherat kelak. Kinanthi juga berarti usia memasuki jenjang perkawinan. Saat yang tepat untuk penentuan jodoh (kekasih yang akan "dikanthi" menuju hidup. Dalam penentuan jodoh, seseorang sampai pada : (a) Kinanthi Mangu, ragu-ragu atau hati-hati dalam memilih. Jika telah mantap, ia akan mendapatkan (b) Kinanthi Sekargadhing, artinya bunga kuning (kekasih) yang menjadi dambaan, kekasih tersebut hendaknya seperti (c) Kinanthi Kaselir, yaitu silir berati seimbang dalan hal cinta, jika hal ini tercapai kedua paduan kekasih bisa memasuki (d) Kinanthi Pantiasri, yaitu pelaminan dan tempat yang begitu indah dan suci, untuk melaksanakan niat mencapai 'rasa sejati' pun perlu memperhatikan aspek waktu yang menurut konteks Jawa setelah (e) Kinanthi Sirep Lare yaitu waktu malam.

Dhandanggula, adalah masa jaya-jayanya seseorang. Ia benarbenar (jika berhasil) akan merasakan manisnya (nikmat) hidup. Pada saat telah hidup berumah tangga, pasangan itu akan (a) Dhandanggula Padhasih, saling memadu kasih untuk mendapatkan keturunan, untuk hal ini diperlukan (b) Dhandhanggula Banjet (bujukan), yaitu rayuan yang memikat, jika ini berhasil, pasangan itu akan mendapatkan 'ultimate feeling' (rasa sejati) yaitu 
(c) Dhandhanggula Kanyut, seperti orang yang hanyut dalam impian indah, ini terlaksana akan mendapat (d) Dhandhanggula Majasih, yaitu buah dari 'asih' (anak) ia akan segera (e) Dhandhanggula Turu Lare, dan (f) Dhandanggula Liksuling yaitu menimang-nimang anak, saat-saat inilah sering timbul (g) Dhandanggula Rencasih, gangguan 'asih' (hidup), oleh karena itu bukan mustahil jika pasangan tadi sering juga merasa (h) Dhandanggula Tlutur, sedih, namun situasi ini justru ujian bagi pasangan untuk segera memikirkan (i) Dhandanggula Baranglaya, mati yaitu bekal yang akan dibawa jika nanti telah sampai (j) Dhandanggula Pasowanan.

Gambuh, artinya tahu. Masa ini melukiskan perjalanan hidup manusia ketika sudah tua. Dalam istilah Jawa, disebut sudah gambuh salwiring kawruh, artinya sudah banyak makan garam. Oleh sebab itu ada bermacam-macam gambuh, yaitu: (b) gambuh gagatan, gagat artinya "wiwit" (awal), ia mulai mengawali masa tua yang dikenal dengan istilah mendhita, (b) Gambuh Wewarah, biasanya tua sering memberi nasehat dan pesan-pesan kepada anak cucu, (c) Gambuh Panglipur, ia juga senang momong cucu dengan rengeng-rengeng (berdendang) lagu-lagu yang telah memfolklor, (d) Gambuh Lala, ia senang menina bobokkan dengan lagu misalnya tak leladhung, hal ini merupakan kebahagiaan tersendiri pada masa tua..

Durma, adalah usia manusia tua biasanya telah undur (menghindar) dari segala keinginan, terlebih lagi hal-hal yang kurang baik. Itulah sebabnya ada Durma: (a) Durma Guntur, artinya longsor, mulai meninggalkan cita-cita hidup yang tidak mungkin tercapai, (b) Durma Suminggah, telah menghindar dari perbuatan yang negatif, (c) Durma Rangsang, ia sudah mulai nggayuh (berusaha) "ke atas" dengan tekun untuk kembali kepada Tuhan.

Maskumambang, sebagai falsafah hidup manusia pada saat sudah "ngambang" (menjelang kematian), mungkin hidupnya tinggal menunggu waktu dan kurang berarti. Maskumambang ada beberapa macam, yaitu: (a) Maskumambang Layu, ibarat bunga, manusia telah keriput, tinggal menunggu takdir (ajal), (b) Maskumambang Kembang Tiba, ia telah "pasrah".

Megatruh, artinya perpisahan jiwa dan raga (mati). Pada saat ini ada Megatruh: (a) Megatruh Lara Nangis, ia sangat sedih karena sudah pisah dengan dengan segala hal, (b) Megatruh Malatsih, ia mencoba minta 
kasih Tuhan agar segala amal perbuatannya diterima, (c) Megatruh

Dudukwuluh dan Megatruh Wuluh Gadhing, saat ini ia melihat warna "wuluh" (ungu tua kekuning-kuningan), pertanda ajal telah datang, akhirnya roh pisah dengan jasat, menuju "nduduk" (ke atas).

Pocung, artinya jika orang telah mati akan dipocong atau dibungkus seperti pocongan, maka ada: (a) Pocung Tunjung Seta, ia diberi "tunjung" (bunga-bungaan) berwarna putih dan dibungkus dengan kain putih, harapannya pun akan mendapatkan kesucian, maka ada (b) Pocung Madusita, sita artinya putih dan madu (kemanisan). Ia berharap dosanya terhapus dan mendapatkan tempat yang layak.

Pangkur, bagi manusia saat ini telah "mungkur" (pergi) dari dunia. Namun, ia masih ada alam lagi yang akan dilewati, yaitu: (a) Pangkur Rambangan, artinya yaumul khisab, amal dan perbuatannya akan "dirambang", ditimbang mana yang baik dan buruk, (b) Pangkur Paripurna, ia telah selesai tugas hidupnya, telah kembali kepada Tuhan.

Ketiga penafsiran TM sebagai falsafah perjalanan hidup tersebut pada prinsipnya sama, yaitu ke arah bahwa hidup itu "berproses" (bergerak). Hidup manusia itu ada asal dan tujuannya, atau ada sangkan paraning dumadi. Namun, dalam menafsirkan ada jenis TM yang dimaknakan sama dan ada pula yang berbeda.

TM yang dimaknai sama, antara lain Mijil (kelahiran), Asmaradana (jatuh cinta), Megatruh (perpisahan jiwa dan raga/mati). Sedangkan TM yang paling menyolok perbedaannya terletak pada penafsiran Kinanthi dan Maskumambang. Baik persamaan maupun perbedaan sebenarnya sah-sah saja, sebab semua ada keutuhan makna dan didasarkan atas othak-athik mathuk serta prinsip budaya spiritual Jawa.

\section{E. Simpulan}

Dari pembahasan di atas dapat disimpulkan bahwa ada dua macam wawasan hidup dalam TM. Pertama, TM menggambarkan wawasan hidup Jawa untuk berdakwah. Kedua, TM menggambarkan wawasan perjalanan hidup.

Wawasan hidup pertama menunjukkan bahwa TM merupakan "wahana" (metode) proses penanaman ajaran. Penanaman ajaran religi hendaknya disampaikan secara menyenangkan dan menghindarkan diri dari pemakaian kata yang dapat melukai hati. Dengan cara ini manusia akan 
tertarik (tanpa paksaan) dan akhirnya akan berhasil mendekatkan diri kepada Tuhan.

Jika demikian dapat diketengahkan bahwa TM merupakan gambaran wawasan hidup epistemologi, yaitu bagaimana manusia mencari pengetahuan tentang Tuhan.

Hal tersebut dapat dipahami, karena pada awalnya wali sanga dalam menanamkan ajaran justru dapat manjing ajur-ajer dengan masyarakatnya. Mereka berusaha mendalami TM, sebab setidaknya mereka percaya bahwa ada kaitan antara TM dengan falsafah nilai khususnya wawasan estetika

Di samping itu nama-nama TM juga melukiskan wawasan perjalanan hidup manusia. Hidup manusia mengalami proses (bergerak dan berkembang) mulai sebelum lahir sampai setelah mati. Wawasan perjalanan hidup dalam TM ini ada sedikit perbedaan, terutama TM kinanthi. Satu pihak menyatakan bahwa kinanthi terletak pada bagian akhir hidup, yaitu sebuah retoris; apa yang akan dikanti. Di pihak lain, kinanthi terkait dengan masa perkawinan seseorang, yaitu hidup perlu kanthi (teman hidup).

Memang perlu disadari, khususnya penafsiran variasi TM memang tidak semua varian bisa ditafsirkan ke arah wawasan perjalanan hidup. Hal ini mengingat bahwa wawasan hidup itu harus bergerak (berproses) menuju sebuah konsep yang utuh. Sedangkan varian TM yang ada sekarang, mungkin memang sudah "kelahiran" baru, sehingga bukan mustahil jika tidak dimaksudkan agar berhubungan dengan wawasan hidup Jawa.

\section{DAFTAR PUSTAKA}

Arintoko. B. 1982. Macapat. Yogyakarta: Dinas P \& K. 1983. Lagu Jawi.

Yogyakarta: Dinas P \& K.

Ciptoprawiro, Abdullah. 1986. Filsafat Jawa. Jakarta: BalaiPustaka.

Darmoatmodjo. 1974. Seni Macapat Wiwit Ngrembaka. Surabaya:

Jaya Baya, 12 Nopember

Darusuparapto. 1989. Tembang Macapat dalam Khasanah Sastra Jawa. Yogyakarta: FS UGM.

Guritno, Pandam. 1995. Pangothak-athik Ngengingi Urutan lan Werdining

Sekar-sekar Macapat. Surabaya: Panjebar Semangat, 30 September.

Harjowiyono, Harujono. 1994. Tradisi Lisan Macapat. Yogyakarta: 


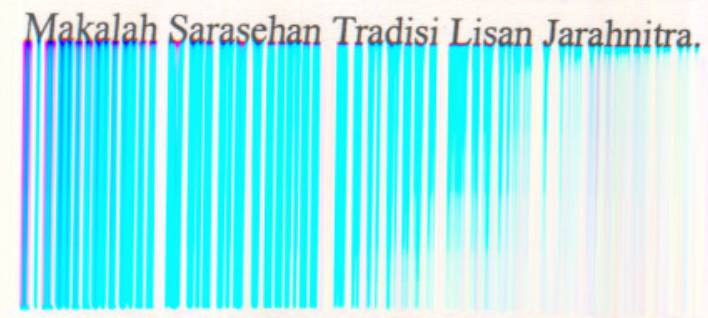

Josodipuro, KRMH. Macapat Versi Kraton Surakarta. Yogyakarta:

DL, 1990: Nop.

Jumiran. 1996. Inovasi Tembang Jawa. Malang: Makalah KBJ II.

Laginem. 1989. Tembang Macapat dalam Serat Wedhatama.

Yogyakarta: Balai Penelitian Bahasa.

1992. Macapat Tradisional dalam Bahasa Jawa.Yogyakarta:

Proyek Penelitian Bahasa dan Sastra Indonesia dan Daerah.

Prabowo, Dhonu Priyo. 1992. Tema Macapat Modern dalam Kandha

Raharja. Tahun 1988. Yogyakarta: Widyaparwa.

1993. Macapat Plesetan Sebuah Bukti Aktualisasi Sastra Jawa.

Yogyakarta: Balai Penelitian Bahasa.

Pardiyono, Panyono. 1993. Tembang Macapat Masih Perlu Kebera daannya. Yogyakarta: Makalah BKS UGM.

Prawiradisastra, Sadjijo. 1997 Pengantar Apresiasi SeniTembang.

Yogyakarta: Diktat Kuliah

Suprihati, Woro Sri, dkk. 1994. Pergeseran Tema Macapat Dari

Zaman Islam Ke Zaman Modern. Yogyakarta: Puslit

Salam, Solichin, 1960. Sekitar Wali Sanga. Kudus: Menara.

Suharjendra, E. 1996. Macapatan Sebagai Sarana Pelestarian dan

Pengembangan Sastra Jawa. Malang: Makalah KBJ II.

Sujamto. 1992. Pandangan Hidup Jawa. Semarang: Effhar Publish

Supadjar, Damarjati. 1996. Fislafat Jawa. Yogyakarta: Makalah

HMJ Jurusan Pendidikan Bahasa Daerah

Sastrasoepadma. 1954. Kasusastraan Djawa. Yogyakarta:Sujadi.

Sujarwi, M. 1976. Macapat Indonesia. Yogyakarta: Asco.

Paedjosoebroto. R. 1978. Wayang Lambang Ajaran Islam. Jakarta:

PT Pradnya Paramita

Widayati, Sri Wahyu. 1993. Tembang Macapat Lamongan. Salah Satu Guru Tembang Macapat Pesisiran. Yogyakarta: Makalah BKS FS UGM. 